\title{
Is Brazil going to achieve the road traffic deaths target? An analysis about the sustainable development goals
}

\author{
Cauane Blumenberg, Rafaela C Martins, Janaína Calu Costa, Luiza I C Ricardo
}

\begin{abstract}
- Additional material is published online only. To view please visit the journal online (http://dx.doi.org/10.1136/ injuryprev-2017-042473).
\end{abstract}

Postgraduate Programme in Epidemiology, Universidade Federal de Pelotas, Pelotas, Rio Grande do Sul, Brazil

\section{Correspondence to} Cauane Blumenberg, PostGraduate Programme in Epidemiology, Federal University of Pelotas, Marechal Deodoro St. 1160, Pelotas, RS 96010610, Brazil; cauane.epi@gmail. com

Received 31 May 2017 Revised 26 July 2017 Accepted 8 August 2017 Published Online First 7 September 2017
Check for updates

To cite: Blumenberg $C$ Martins RC, Calu Costa J, et al. Inj Prev

2018:24:250-255

\begin{abstract}
Objective To describe the temporal relationship between the road traffic mortality rate and gross domestic product (GDP) per capita in Brazil, and make an annual prediction of the evolution of both indicators until 2020, the end of the Sustainable Development Goals (SDGs) monitoring period.

Methods Brazilian road traffic mortality rate official data were described from 2000 to 2015, while the GDP per capita official data were described from 2000 to 2013. GDP per capita and traffic mortality rate predictions were performed until 2020 using fractional polynomial analysis. Correlations were assessed using Pearson's correlation coefficient.
\end{abstract}

Results From 2000 to 2015, there were over 446000 road crashes fatal victims in Brazil. The road traffic mortality rate was positively related to the Brazilian GDP per capita, with a strong correlation $(r=0.89$; $p<0.001$ ) from 2000 to 2013 and a mild correlation $(r=0.55 ; p<0.001)$ considering the whole period (2000-2020). The predictions show a reduction on the road traffic mortality rates in Brazil; however, if this same reduction pace continues, we estimate that the country will reach 12.4 road crash deaths per 100000 inhabitants in 2020, a reduction of only $13.4 \%$ compared with 2015.

Conclusion If the same mortality reduction pace continues in Brazil, the country will not reach the proposed SDG, which is to reduce by half the number of deaths per 100000 inhabitants. In addition, an intertwined conciliation between economical growth, sustainable development and public policies is needed in order to meet such an overwhelming goal.

\section{INTRODUCTION}

Road traffic injuries are an important public health problem and cause of disability, and it is estimated that between 20 and 50 million people suffer from non-fatal injuries, which are an important cause of disability. ${ }^{1}$ Additionally, it is one of the leading causes of preventable deaths worldwide, responsible for more than 1.2 million deaths each year, ${ }^{2}$ and the main cause of death among people between 15 and 29 years of age, almost half of all these deaths being among pedestrians, cyclists and motorcyclists. ${ }^{3}$ Due to the large volume of worldwide deaths resulting from road traffic crashes (RTCs), the WHO initiated, in 2010, the 'Decade of Action for Road Safety - 2011-2020'. This action set a global goal of stabilising and then reducing the forecasted level of global road fatalities by increasing activities conducted at national, regional and global levels. ${ }^{1}$

In September 2015, countries adopted a set of goals to end poverty, protect the planet and ensure health and prosperity for all as part of a new sustainable development agenda. Each goal has specific targets to be achieved over the next 15 years. With the launch of these Sustainable Development Goals (SDGs), road safety is receiving increased international attention, and will be monitored as an indicator included in the global agenda. ${ }^{2}$ The target is to reduce road traffic fatalities by $50 \%$ by 2020 , aiming on sustainable urban transport to seek a global road-safe community. ${ }^{5}$

One challenge that countries will face is to reach the proposed target, allied to their economic growth. On the one hand, a higher economic development leads to higher road provision and better road quality, increasing road safety. ${ }^{6} 7$ On the other hand, economic development increases the level of motorisation of a country, also increasing the number of crashes and deaths. ${ }^{8-10}$ Despite the increase in global motorisation and population, since 2007 the total absolute number of road traffic deaths around the world became stable. ${ }^{11}$ However, there is a great disparity by country income. While the highest road traffic mortality rates are in low-income and middle-income countries (LMICs), the fatalities continue to decrease in high-income countries. ${ }^{11}$ For instance, in Brazil, a middle-income country, the gross domestic product (GDP) per capita increased from I\$3481.9 (I\$-international dollars) in 2000 to I\$13256.1 in 2013; however, the road traffic mortality rate has also increased from 10.4 deaths to 16.2 deaths per 100000 inhabitants. $^{12}$ The 2013 estimate placed Brazil as one of the leaders in road traffic mortality rate when compared with the global rate (17.1 deaths per 100000 persons). ${ }^{2}$ These issues go on the opposite direction of the country economic growth, since road traffic deaths can cause up to $6 \%$ of GDP loss. $^{13}$

Some studies have evaluated the association between road traffic mortality and economic aspects of the countries where they occur. ${ }^{9} 1014-16$ Results indicate that road traffic mortality rates can be influenced by the GDP per capita, and it implies that a lower economic development worsens the road safety situation. ${ }^{14} 15$ Other studies state that a country's economy impacts other aspects related to road traffic mortality, such as road conditions, police enforcement and adequate emergency 
treatment for trauma care. ${ }^{1016} \mathrm{~A}$ study also evaluated the impact of the rapid economic growth on the level of motorisation and road safety, describing a significant increase on traffic fatalities. ${ }^{9}$

Brazil economically grew in recent years, and it is important to study the relation of the country's economic development with its road safety. Therefore, the aim of the present study is to describe the temporal relationship between the road traffic mortality rate and the GDP per capita in Brazil, and make an annual prediction of the evolution of both indicators by the end of the SDGs monitoring period in order to assess if Brazil will achieve the goal of halving the road traffic fatalities by 2020 .

\section{METHODS}

A descriptive analysis using data about road traffic mortality rate from 2000 to 2015, and GDP per capita from 2000 to 2013, was performed. Road traffic mortality rate predictions were made from 2016 to 2020, while for the GDP per capita the predictions were made between 2014 and 2020.

Data related to death certificates were obtained from the Mortality Information System (Sistema de Informação sobre Mortalidade (SIM) $)^{12}$ of the Ministry of Health, provided by the Informatics' Department of the Unified Health System. Deaths related to road traffic were selected according to the International Statistical Classification of Diseases and Related Health Problems-10 under the codes V01 to V29 and V40-V79, which were grouped according to the victim, as follows: pedestrian (pedestrian injured in transport crash, V01-V09); cyclist (cyclist injured in transport crash, V10-V19); motorcyclist (motorcycle rider injured in transport crash, V20-V29); car occupant (occupant injured in automobile transport crash, V40-V49); and heavy vehicle occupant (truck occupant traumatised in a transport crash, V50-V59; heavy transport vehicle occupant injured in transport crash, V60-V69; and bus occupants injured in transport crash, V70-V79). ${ }^{17}$

Information about population size and GDP per capita was obtained from the Brazilian Institute of Geography and Statistics (IBGE).$^{18}$ The population size data are a projection performed by the IBGE, and data from 2000 to 2015 were used in this study. The GDP per capita data were available from 2000 to $2013^{19}$ and were already calculated by the IBGE in the Brazilian currency, expressing the ratio between GDP and the resident population. To convert the GDP estimates to international dollars, the values were divided by 1.99 , the 2016 Brazil's purchasing power parity (PPP) obtained from the World Bank ${ }^{20}$ data. The Brazilian PPP value was used to calculate the GDP per capita for each federation unit (FU), since PPP values per FU were not available.

Annual road traffic mortality rates for the period from 2000 to 2015 were calculated by dividing the number of deaths (by place of occurrence) by the resident population per 100000 inhabitants. The road traffic mortality rates were calculated for each FU and for the whole country, and were age-standardised by direct standardisation. The total Brazilian population from 2000 to 2015 was considered as the standard population, and nine age categories were considered in order to calculate the standard rates ( $0-4$ years, $5-14$ years, $15-24$ years, $25-34$ years, $35-44$ years, $45-54$ years, $55-64$ years, $65-74$ years and 75 years or more).

To estimate road traffic mortality rates and GDP per capita in Brazil and per FU, the first-degree and second-degree fractional polynomials (FP) were tested. The road traffic mortality rate and the GDP per capita FP models were adjusted separately, both containing only the year as a predictor. To predict the road traffic mortality rates in Brazil from 2016 to 2020, the second-degree
FP using twice the year variable powered to $(3,3)$ achieved the best fit. Since this is a repeated power model, the first year coefficient is powered to 3 (ß1), and the second is powered to 3 and multiplied by its natural $\log (B 2)$ (adjusted $\mathrm{R}^{2}=0.90 ; \mathrm{p}<0.001$ ). For the Brazilian GDP per capita predictions from 2014 to 2020, the best fit was also obtained using a repeated second-degree FP model $(3,3)$ (adjusted $\mathrm{R}^{2}=0.99 ; \mathrm{p}<0.001$ ).

In order to predict, for each $\mathrm{FU}$, the road traffic mortality rate from 2016 to 2020 and the GDP per capita from 2014 to 2020, subnational data were used. The same FP methodology used to predict the national estimates was applied. The first-degree and second-degree FPs containing the year as unique covariate were tested for each one of the 27 FUs, and the best fit was used to predict the estimates. The models used to predict the age-standardised road traffic mortality rates and the GDP per capita were adjusted separately. The graphs describing the FP models used to predict the age-standardised road traffic mortality rate for each FU are presented in online supplementary file 1, while the GDP per capita predictive models for each FU are presented in online supplementary file 2 .

The differences between proportions were tested using two-sample test of proportions. The correlation between aggregate road traffic mortality rate and GDP per capita was assessed using Pearson's correlation coefficient (r). Linear regression models were used to analyse per-year variation on the considered indicators. It was considered a 5\% significance level. Data processing and statistical analysis were performed using Excel (Microsoft, Redmond, Washington, USA) and the Stata V.13 software.

The present study used data from public domain surveillance systems, so there is no possibility of identification of the subjects studied. Therefore, the study is classified as freed from the need for consideration by an ethical committee as established in the Resolution of the Brazilian National Health Council 466, 12 December 2012. ${ }^{21}$

\section{RESULTS}

From 2000 to 2015, in Brazil, there were over 446000 fatal victims due to road crashes. As shown in table 1, in the period from 2000 to 2007, the majority of the fatal victims were pedestrians, which accounted for $41.2 \%$ of the deaths. However, this was the only type of victim that suffered a reduction on the absolute number of deaths due to road crashes for the period from 2008 to 2015. A reduction of over 9000 deaths of pedestrians and a significant increase in the number of deaths of motorcyclists and car occupants in the period from 2008 to 2015 turned the pedestrians to be the third type of fatal victim due to road crashes. In this later period, the number of absolute deaths of motorcyclists more than doubled, and hence the motorcycle was the leading cause of death, being responsible for $35.0 \%$ of the total fatal victims.

Table 1 Total number of fatal victims due to road crashes in Brazil according to type of victim, from 2000 to 2007, and from 2008 to 2015

\begin{tabular}{lccc}
\hline & \multicolumn{2}{c}{ Fatal victims due to road crashes $(\mathrm{n})$} & \\
\cline { 2 - 3 } Type of fatal victim & $\mathbf{2 0 0 0 - 2 0 0 7 ( \% )}$ & $\mathbf{2 0 0 8 - 2 0 1 5 ( \% )}$ & p Value \\
\hline Pedestrian & $78644(41.2)$ & $69561(27.3)$ & $<0.001$ \\
Cyclist & $10529(5.5)$ & $11684(4.6)$ & $<0.001$ \\
Motorcyclist & $39836(20.8)$ & $89557(35.0)$ & $<0.001$ \\
Car occupant & $53649(28.1)$ & $73898(29.0)$ & $<0.001$ \\
Heavy vehicle occupant & $8409(4.4)$ & $10543(4.1)$ & $<0.001$ \\
\hline Total & $191067(100.0)$ & $255243(100.0)$ & \\
\hline
\end{tabular}




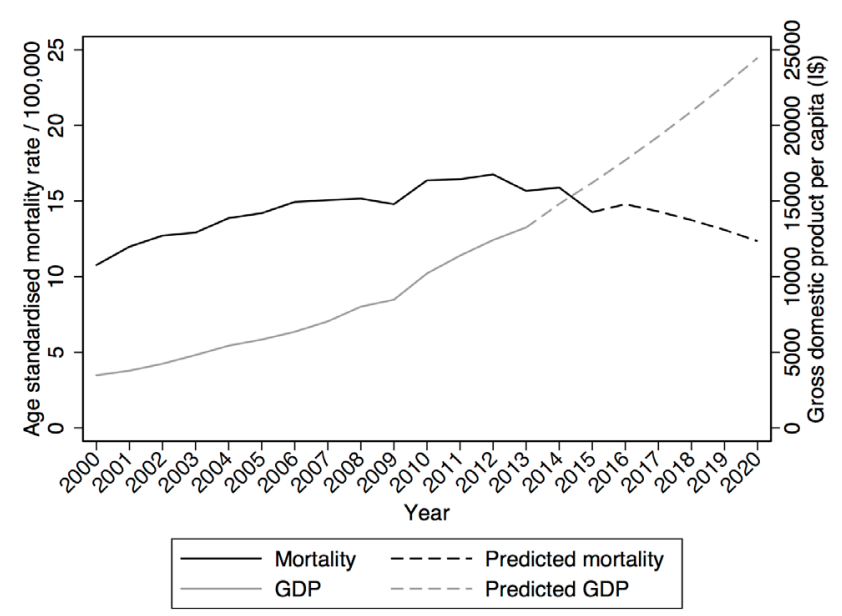

Figure 1 Age-standardised road traffic mortality rate in Brazil and the Brazilian gross domestic product per capita. Road traffic mortality rate predictions are presented from 2016 to 2020, while predictions for the GDP per capita are presented from 2014 to 2020. GDP, gross domestic product.

In figure 1, the age-standardised mortality rate from road crashes per 100000 inhabitants in Brazil and the country GDP per capita are compared. Considering the period from 2000 to 2013, when both indicators had official data available, there was a strong positive correlation between the Brazilian GDP per capita and the road traffic mortality rate $(r=0.89$; $\mathrm{p}<0.001)$. However, when the whole period is considered, the positive correlation between the indicators would become mild $(r=0.55 ; p=0.010)$. In 2015, the most recent year when official data about road traffic mortality were produced, there were around 14.3 deaths per 100000 inhabitants in Brazil, while in 2020 it is estimated that there will be 12.4 deaths per 100000 inhabitants in Brazil-a 13.4\% reduction comparing both years. The prediction would represent a 0.43 road traffic mortality rate reduction per 100000 inhabitants per year for the period from 2015 to 2020 (adjusted $\mathrm{R}^{2}=0.77$; $\mathrm{p}=0.013$ ), whereas comparing the Brazilian GDP per capita estimates from the years 2015 and 2020, an increase equal to $50.9 \%$ on this indicator is predicted.

Data for 2015 and 2020 age-standardised road traffic mortality rate and GDP per capita for each Brazilian FU are presented in table 2. Considering the road traffic mortality rate, official data were used for the 2015 estimates and predictions were performed for 2020. For the GDP per capita estimates, both years were predicted. In table 2 , the arrows pointing down represent a predicted statistically significant $(\mathrm{p}<0.05)$ reduction on the trend of traffic mortality from 2015 to 2020, the arrows pointing up represent a statistically significant increasing trend, and the squares represent a predicted stationary trend. From 2015 to 2020, the estimated road traffic mortality rate trends would increase in $40.8 \%$ of the FUs and would reduce in $29.6 \%$.

\begin{tabular}{|c|c|c|c|c|c|c|}
\hline \multicolumn{3}{|l|}{2015} & \multicolumn{4}{|l|}{2020} \\
\hline Federation unit & MR & GDP per capita* & Federation unit & MR trend* & $\mathrm{MR}^{*}$ & GDP per capita* \\
\hline 1 Roraima & 34.0 & 11070.3 & 1 Piauí & $\Delta$ & 47.6 & 9785.5 \\
\hline 2 Piauí & 32.9 & 6185.3 & 2 Tocantins & $\mathbf{\square}$ & 32.5 & 13702.9 \\
\hline 3 Tocantins & 32.6 & 9450.9 & 3 Sergipe & $\Delta$ & 30.6 & 15191.6 \\
\hline 4 Mato Grosso & 24.5 & 14580.4 & 4 Acre & $\Delta$ & 30.5 & 12250.0 \\
\hline 5 Mato Grosso do Sul & 23.4 & 16935.3 & 5 Mato Grosso & 口 & 28.9 & 18591.5 \\
\hline 6 Sergipe & 23.2 & 10011.0 & 6 Rondônia & $\Delta$ & 28.8 & 13476.3 \\
\hline 7 Rondônia & 21.4 & 10475.3 & 7 Roraima & $\boldsymbol{\square}$ & 28.6 & 16273.1 \\
\hline 8 Santa Catarina & 21.0 & 19409.4 & 8 Maranhão & $\boldsymbol{\Delta}$ & 25.9 & 8837.3 \\
\hline 9 Goiás & 20.8 & 14965.7 & 9 Paraíba & $\Delta$ & 25.5 & 11267.5 \\
\hline 10 Maranhão & 19.2 & 5901.0 & 10 Espírito Santo & $\square$ & 25.1 & 30046.2 \\
\hline 11 Paraná & 18.5 & 18170.0 & 11 Goiás & $\Delta$ & 24.1 & 23687.0 \\
\hline 12 Paraíba & 17.6 & 7330.0 & 12 Pernambuco & $\Delta$ & 20.0 & 15398.4 \\
\hline 13 Ceará & 17.5 & 7659.9 & 13 Pará & $\Delta$ & 17.9 & 15477.6 \\
\hline 14 Pernambuco & 17.5 & 9621.6 & 14 Ceará & $\boldsymbol{\square}$ & 17.6 & 11876.4 \\
\hline 15 Espírito Santo & 17.1 & 20059.4 & 15 Santa Catarina & $\nabla$ & 17.0 & 28591.4 \\
\hline 16 Minas Gerais & 14.9 & 14574.2 & 16 Bahia & $\Delta$ & 15.7 & 11715.5 \\
\hline 17 Distrito Federal & 14.3 & 35448.2 & 17 Rio Grande do Norte & 口 & 14.1 & 15224.2 \\
\hline 18 Pará & 13.3 & 9567.6 & 18 Mato Grosso do Sul & $\nabla$ & 13.8 & 27264.1 \\
\hline 19 Rio Grande do Norte & 13.0 & 9632.8 & 19 Minas Gerais & $\nabla$ & 13.5 & 22180.3 \\
\hline 20 Bahia & 10.9 & 8159.0 & 20 Rio Grande do Sul & $\mathbf{\square}$ & 13.4 & 25859.4 \\
\hline 21 Rio Grande do Sul & 10.9 & 17529.7 & 21 Distrito Federal & घ & 13.1 & 44008.1 \\
\hline 22 Amazonas & 10.7 & 13039.3 & 22 Amazonas & $\Delta$ & 11.0 & 18564.9 \\
\hline 23 Rio de Janeiro & 10.0 & 23655.8 & 23 Paraná & $\nabla$ & 8.4 & 28111.0 \\
\hline 24 Acre & 9.7 & 8601.8 & 24 São Paulo & $\nabla$ & 4.8 & 35895.2 \\
\hline 25 São Paulo & 9.7 & 24109.5 & 25 Rio de Janeiro & $\nabla$ & 1.0 & 37075.6 \\
\hline 26 Amapá & 9.0 & 10353.8 & 26 Alagoas & $\nabla$ & 0.0 & 11295.7 \\
\hline 27 Alagoas & 3.7 & 7214.1 & 27 Amapá & $\nabla$ & 0.0 & 15607.8 \\
\hline
\end{tabular}

*Predicted data.

GDP, gross domestic product per capita in international dollars; MR, age-standardised road traffic mortality rate per 100000 inhabitants. 
In 2020, 6 out of the 13 FUs with predicted GDP per capita values above the median (I\$15 607.80) would have a statistically significant reduction trend on the road traffic mortality rates (Minas Gerais, Mato Grosso do Sul, Paraná, Santa Catarina, São Paulo and Rio de Janeiro) from 2015 to 2020. Five of them would present a stationary trend (Roraima, Mato Grosso, Rio Grande do Sul, Espírito Santo and Distrito Federal), and only Amazonas and Goiás would have statistically significant increases. However, the scenario is different when the 13 FUs with predicted GDP per capita values below the predicted median in 2020 are considered. Nine FUs would have significant increase on their road traffic mortality rate trend (Maranhão, Piauí, Paraíba, Bahia, Acre, Rondônia, Sergipe, Pernambuco and Pará), three would have stationary trends (Ceará, Tocantins and Rio Grande do Norte), and only Alagoas would present a statistically significant decreasing trend from 2015 to 2020.

\section{DISCUSSION}

The present study predicts a trend of increase in the GDP per capita and a smooth decrease on the road traffic mortality rates in Brazil. However, the reduction of $13.4 \%$ on the road traffic mortality rates would not be enough to halve the mortality rate by 2020 as proposed in goal 3.6 of the SDGs. ${ }^{5}$ The road traffic mortality in Brazil is expected to be 12.4 deaths per 100000 inhabitants in 2020; however, it would be necessary to reach 7.2 deaths per 100000 inhabitants to achieve the road safety SDG. If the same road traffic mortality decreasing pace continues, we estimate that Brazil would reach the goal only in 2025, 5 years later from the end of the SDG's monitoring period.

The failure to achieve the road traffic mortality goal in Brazil can be attributed to several factors, which could be intervened. First, the increasing amount of motorised vehicles is a growing concern since it contributes considerably to the set of fatalities and injuries from RTCs in developing countries. ${ }^{10}$ In Brazil, between 2001 and 2012, the amount of cars and motorcycles doubled, reaching 50.2 million in 2012 and corresponding to an increase 11 times greater than the Brazilian population growth. ${ }^{22}$ The high increase on the number of cars and motorcycles is associated with the country's economic development, representing the capability of the population to buy consumer goods. ${ }^{23}$ Wang and colleagues ${ }^{24}$ indicate that in the early stage of economic development, the mortality of RTCs increased along with the economic development, but when the economic development reached a certain level, the mortality decreased. In the early stage of economic development of India and China, both the level of motorisation and the road traffic mortality rates increased. ${ }^{9}$ The same can be seen in Brazil: a steep GDP per capita increasing trend and a higher number of motorcyclists and car occupants victims of fatal road traffic injuries from 2008 to 2015, compared with previous periods.

A second factor that may contribute to traffic mortality rates is the development of roads. Road infrastructure and conditions play an important role, since a high road traffic mortality rate is possibly related with highways decay and inadequate infrastructure. However, this is also an important factor that leads to economic development. Thus, it is not possible to determine a direct causal relationship between economic indicators and deaths resulting from traffic crashes despite the correlation shown by our results. ${ }^{25}$

Another matter to consider is the ability of the public health system in providing adequate treatment for traffic injuries, since a poor public health infrastructure usually means that patients often do not receive appropriate care promptly, increasing the probability of adverse health outcomes and long-term disability. ${ }^{10}$ What is seen between LMICs is that their economic growth boosts motorisation and road traffic injuries, ${ }^{26}$ but the healthcare facilities fail to follow this increase. Therefore, according to Dalal et $a l,{ }^{27}$ Brazil was the sixth in the top 25 countries with the greatest number of disability-adjusted life years due to road traffic injuries in 2004, reflecting a need to improve healthcare in this set of injuries. ${ }^{27}$ Our results estimated an increase in the GDP per capita from 2014 to 2020, and a reduction on the road traffic mortality from 2016 to 2020. This inverse relation between the indicators may represent that the economic development of the country already reflected in the public health services, which in turn influence the reduction of mortality rates. One important healthcare improvement in Brazil was the Mobile Emergency Care Service (Serviço de Atendimento Móvel de Urgência (SAMU)), adopted nationwide in 2003, but with important variations on coverage among Brazilian municipalities. ${ }^{28}$

Compared with other countries in South America, Brazil is at the same time one of the largest economies and the leading country in road traffic mortality. ${ }^{2}$ This important magnitude, both in economy and in mortality rate, can be explained by the huge differences within the country. The fact that the majority of the Brazilian FUs with GDP per capita values above the median present decreasing mortality rate trends can be explained by better conditions of roads and assistance provided to victims. This could also be attributed to better public transportation network and conditions among these FUs, which can decrease the number of private vehicles in the streets and the number of crashes. ${ }^{29}$ In contrast, the increasing trend of road traffic mortality was the most common among the Brazilian FUs with GDP per capita below the median. This happens since these FUs may have worse health assistance, road quality and public transportation conditions. Besides, the increase on the motorcycle fleet plays a role in the differences between mortality rates of the Brazilian FUs, as the number of motorcyclists increased by $72 \%$ among the poorest FUs, and by $33 \%$ among the ones with GDP values above the median. ${ }^{22}$

Fortunately, Brazil has an important set of laws for the promotion of traffic safety that could contribute to a greater reduction of the road traffic mortality rates: for example, the inhibition of alcohol consumption by motor vehicle drivers, obligation of the front air bag installation for driver and front seat passenger, regulating the exercise of professional activities in passenger transport and delivery of goods, and more severe punishments of dangerous behaviours. ${ }^{30}$ The implementation of the law related to alcohol consumption, in 2008, may have contributed to the reduction of the mortality in the following year, as shown in figure 1 . However, regional differences in the country are again observed. According to the 2013 Telephone Based Surveillance of Risk and Protective Factors for Chronic Diseases (Vigilância de Fatores de Risco e Proteção para Doenças Crônicas por Inquérito Telefônico (VIGITEL)), the frequency of 18 -year-old adults who reported driving a motor vehicle after consuming any amount of alcohol varied from $3.0 \%$ to $14.0 \%$ across the country's FUs. ${ }^{31}$ We need to interpret these data with caution and consider that there may be under-reporting since the practice of driving after alcohol consumption is punishable according to the law. ${ }^{32} 33$ Even so, this shows the lack of enforcement in Brazil, since 5 years after its creation, young drivers are no more respecting the law. ${ }^{34}$ In addition, Brazilian drivers present low awareness of the content of the law. ${ }^{35}$ Hypothetically, the implementation of alternative policies such as the Swedish 'Vision Zero', ${ }^{36}$ which shares the responsibility of 
road safety between government and road users, could lead to a better scenario in Brazil.

The present study shows some limitations. Although the Brazilian government had improved the surveillance on crashes by creating the Surveillance System Violence and Accidents (Sistema de Vigilancia de Violência e Acidentes (VIVA) $)^{37}$ in 2006, some official data are still doubtful. Referring to online supplementary file 1 , it is possible to note a huge variability in the estimates of some FUs (eg, Amapá and Roraima). These could be due to the low quality of reporting traffic mortalities and injuries in these locations. Another limitation is related to the road traffic mortality predictions for 2020, since three FUs (Rio de Janeiro, Alagoas and Amapá) would have values close to 0 . Our predictions were based on the period when official data were available, and we applied the same trend for the following years. Although some extreme values occur, the use of FPs is a common approach to perform estimate predictions. ${ }^{38}$ Finally, the absence of updated GDP per capita data generated a predicted steep increasing trend of this indicator. However, it is known that Brazil was affected in the recent years by an economic crisis. For this reason, we believe our GDP per capita predictions could be overestimated.

\section{CONCLUSION}

Although the predictions showed that Brazil is reducing the road traffic mortality rates, if this same reduction pace continues the country will not reach the goal of reducing by half the rate of deaths due to traffic crashes by 2020, as suggested by the WHO's SDGs. This is a big challenge for LMICs, since there is a need to reach a balance between economical development, increase on motorisation, and development of road and

\section{What is already know on the subject}

- Road traffic mortality is an important public health problem, being one of the leading causes of preventable death worldwide. Due to this reason, it was included in the Sustainable Development Goals (SDG) agenda proposed by the WHO.

- Although there was an increase in global motorisation and population, the absolute number of road traffic deaths around the world became stable. However there is a great disparity by country income.

- Brazil is facing a rapid economic growth, but also occupies the leading places of the road traffic mortality rate ranking.

\section{What this study adds}

- Different from what happened at the global level, in Brazil the road traffic mortality rate increased from 2000 to 2012. The predictions show that the road traffic mortality rates would smoothly decrease until 2020, when the period of the SDG agenda ends.

- In Brazil, from 2000 to 2013, there was a strong correlation between road traffic mortality and gross domestic product. A mild correlation is predicted until 2020. It is a challenge for the country to balance between economic development and road safety.

- If the same road traffic mortality reduction pace continues, Brazil will not be capable of halving the road traffic mortality rate by 2020 as proposed by the SDGs. primary care infrastructure. In order to achieve the proposed SDG goal, an urgent integration between national and regional policies is needed, including the implementation of educational programme to increase awareness of the legal restrictions and its consequences, increase the coverage of healthcare services such as SAMU, and increase the enforcement of road traffic laws.

Correction notice This article has been corrected since it was published Online First. The name of the third author, Janaina Calu Costa, has been corrected.

Contributors All authors elaborated the design of the study. CB performed the statistical analyses, and contributed to writing and revising the manuscript. RCM collected the data, and contributed to writing and revising the manuscript. JCC and LICR contributed to writing and revising the manuscript. All authors critically revised and approved the final version of this manuscript.

Competing interests None declared.

Provenance and peer review Not commissioned; externally peer reviewed.

Data sharing statement All data used in this study are publicly available in the Brazilian registries. Refer to the reference list in order to locate the links to retrieve the data.

(c) Article author(s) (or their employer(s) unless otherwise stated in the text of the article) 2018. All rights reserved. No commercial use is permitted unless otherwise expressly granted.

\section{REFERENCES}

1 World Health Organization. Global Plan for the Decade of Action for Road Safety 2011-2020. 2010 http://www.who.int/roadsafety/decade_of action/plan/en/.

2 World Health Organization. Global status report on road safety: time for action. Geneva: World Health Organization, 2009. http://public.eblib.com/choice/ publicfullrecord.aspx?p=557632 (accessed 21 Oct 2016).

3 Brasil. Brasilia Declaration on Road Safety: 2nd Global High Level Conference on Road Safety. 2015 http://www.who.int/violence_injury_prevention/road_traffic/Brasilia_ Declaration/en/.

4 Buse K, Hawkes S. Health in the sustainable development goals: ready for a paradigm shift? Global Health 2015;11:13.

5 World Health Organization. Sustainable Development Goal 3: Ensure healthy lives and promote well-being for all at all ages. $2015 \mathrm{https}$ ://sustainabledevelopment.un.org/ sdg3 (accessed 21 Oct 2016).

6 Ingram GK, Liu Z. Motorization and the Provision of Roads in Countries and Cities. The World Bank 1999 http://elibrary.worldbank.org/doi/book/ (accessed 21 Oct 2016)

7 Mohan D. Road safety in less-motorized environments: future concerns. Int J Epidemiol 2002;31:527-32.

8 Kopits E, Cropper M. Traffic fatalities and economic growth. Accid Anal Prev 2005;37:169-78

9 Pucher J, Peng Z-ren, Mittal N, et al. Urban Transport Trends and Policies in China and India: Impacts of Rapid Economic Growth. Transp Rev 2007;27:379-410.

10 Nantulya VM, Reich MR. The neglected epidemic: road traffic injuries in developing countries. BMJ 2002;324:1139-41.

11 World Health Organization. Global status report on road safety 2015. Geneva: World Health Organization, 2015. http://www.who.int/violence_injury_prevention/road_ safety_status/2015/GSRRS2015_Summary_EN_final2.pdf?ua=1. (accessed 17 May 2017).

12 Brasil, Ministério da Saúde. Sistema de Informação sobre Mortalidade. Sist Informação Sobre Mortalidade 2016 http://portalsaude.saude.gov.br/index.php/o-ministerio/ principal/secretarias/svs/mortalidade (accessed 31 May 2017).

13 Wijnen W, Stipdonk H. Social costs of road crashes: An international analysis. Accid Anal Prev 2016;94:97-106.

14 Gaygisiz E. Economic and cultural correlates of road-traffic accident fatality rates in OECD countries. Percept Mot Skills 2009;109:531-45.

15 Ernstberger A, Joeris A, Daigl M, et al. Decrease of morbidity in road traffic accidents in a high income country - an analysis of 24,405 accidents in a 21 year period. Injury 2015;46(Suppl 4):S135-43.

16 Hazen A, Ehiri JE. Road traffic injuries: hidden epidemic in less developed countries. J Natl Med Assoc 2006;98:73-82.

17 World Health Organization. International statistical classification of diseases and related health problems. 2016.

18 Instituto Brasileiro de Geografia e Estatística. Censo Demográfico 2010. 2011 http:// www.ibge.gov.br/home/estatistica/populacao/censo2010/default.shtm.

19 Instituto Brasileiro de Geografia e Estatística. Produto Interno Bruto dos Municipios 2010-2013. 2014 http://www.ibge.gov.br/home/estatistica/economia/ pibmunicipios/2010_2013/default.shtm. 
20 World Bank. PPP conversion factor, GDP (LCU per international \$). Int Comp Program Database 2016 http://data.worldbank.org/indicator/PA.NUS.PPP (accessed $21 \mathrm{Jul}$ 2017).

21 Brasil, Ministério da Saúde. Resolução no466 de 12 de dezembro de 2012. 2012

22 Departamento Nacional de Trânsito. Frota de veículos. 2017 http://www.denatran. gov.br/estatistica/237-frota-veiculos (accessed 24 Jul 2017).

23 Yang Z, Jia P, Liu W, et al. Car ownership and urban development in Chinese cities: A panel data analysis. J Transp Geogr 2017;58:127-34.

24 Wang C, Chi GB, Wang SY, et al. [The relationship between secular trend of road traffic injuries and gross domestic product per capita in China]. Zhonghua Yu Fang $Y_{i}$ Xue Za Zhi 2011;45:350-3.

25 Híjar M, Chandran A, Pérez-Núñez R, et al. Quantifying the underestimated burden of road traffic mortality in Mexico: a comparison of three approaches. Traffic Inj Prev 2012;13(Suppl 1):5-10.

26 Stevenson M, Thompson J, de Sá TH, et al. Land use, transport, and population health: estimating the health benefits of compact cities. Lancet 2016;388:2925-35.

27 Dalal K, Lin Z, Gifford M, et al. Economics of global burden of road traffic injuries and their relationship with health system variables. Int J Prev Med 2013;4:1442-50.

28 Machado CV, Salvador FGF, O'Dwyer G. Serviço de Atendimento Móvel de Urgência: análise da política brasileira. Rev Saude Publica 2011;45:519-28.

29 Rojas-Rueda D, de Nazelle A, Teixidó 0 , et al. Replacing car trips by increasing bike and public transport in the greater Barcelona metropolitan area: a health impact assessment study. Environ Int 2012;49:100-9.

30 Brasil. Constituição da República Federativa do Brasil de 1988. 1988 https:// legislacao.planalto.gov.br/legisla/legislacao.nsf/viwTodos/509f2321d97cd2d20325
6b280052245a?OpenDocument\&Highlight=1, constitui\%C3\%A7\%C3\%A3o\& AutoFramed (accessed 20 Oct 2016).

31 Brasil. Vigitel Brasil 2014: vigilância de fatores de risco e proteção para doenças crônicas por inquérito telefônico. Ministério da Saúde 2015 http://bvsms.saude.gov. br/bvs/publicacoes/vigitel_brasil_2014.pdf.

32 Malta DC, Berna RT, Silva MM, et al. Consumption of alcoholic beverages, driving vehicles, a balance of dry law, Brazil 2007-2013. Rev Saude Publica 2014;48:692-966.

33 Moura EC, Malta DC, Morais Neto OL, et al. Direção de veículos motorizados após consumo abusivo de bebidas alcoólicas, Brasil, 2006 a 2009. Rev Saude Publica 2009;43:891-4.

34 Craide S, Bocchini B, Nogueira E. Após 4 anos de tolerância zero na Lei Seca, motoristas ainda resistem a mudanças. EBC Agência Bras 2016 http://agenciabrasil. ebc.com.br/geral/noticia/2016-04/apos-4-anos-de-tolerancia-zero-lei-seca-motoristasainda-resistem-a-mudar-habitos (accessed 26 Jul 2017).

35 da Conceição TV, De Boni R, Duarte PC, et al. Awareness of legal blood alcohol concentration limits amongst respondents of a national roadside survey for alcohol and traffic behaviours in Brazil. Int J Drug Policy 2012;23:166-8.

36 Johansson R. Vision Zero - Implementing a policy for traffic safety. Saf Sci 2009;47:826-31.

37 Brasil. Portaria MS/GM n 1.356 de 23 de junho de 2006. Instituiu incentivo para a Vigilância de Acidentes e Violência em Serviços Sentinela. 2006.

38 Royston P, Ambler G, Sauerbrei W. The use of fractional polynomials to model continuous risk variables in epidemiology. Int J Epidemiol 1999;28:964-74. 